\title{
The social environment is most important for not using snus or smoking among adolescents
}

\author{
Ingrid Edvardsson ${ }^{1}$, Lena Lendahls ${ }^{2}$, Tobias Andersson ${ }^{3}$, Göran Ejlertsson ${ }^{4}$ \\ ${ }^{1}$ Department of Clinical Sciences Malmö, Lund University, Lund, Sweden; \\ ingrid.edvardsson@1tkronoberg.se \\ ${ }^{2}$ Unit for Research and Development, Kronoberg County Council, Kronoberg, Sweden \\ ${ }^{3}$ Kampinas Gard 1, Angelstad, Sweden \\ ${ }^{4}$ School of Health and Society, Kristianstad University, Kristianstad, Sweden
}

Received 1 November 2012; revised 1 December 2012; accepted 9 December 2012

\section{ABSTRACT}

Aims: To identify factors, which were related to being smoke-free and snus-free, respectively, among adolescents in relation to adolescents who were smoking and/or using snus, and determine if there were any sex differences. Methods: A questionnaire study was performed among students in year two in upper secondary schools (17-year-old) in southern Sweden in 2009. More than 2200 students completed the questionnaire regarding health and living habits anonymously. The variables were tested by $\chi^{2}$-test, before selection into the logistic model. Because of the salutogenic approach in the study, the results of the logistic regression analyses were expressed as Positive Odds Ratio (POR). Results: The prevalence of being smokefree was $\mathbf{7 5 . 6}$ percent for girls and $\mathbf{7 0 . 2}$ percent for boys, whilst the prevalence of being snusfree was 95.1 percent for girls and $\mathbf{7 0 . 2}$ percent for boys. Having a tobacco-free best friend was the most important factor that correlated with being smoke- and snus-free as an adolescent, for both boys and girls. Good living habits, such as drinking less alcohol, were also central to being smoke-free and snus-free. Conclusions: The results show that a tobacco-free environment has a great influence on whether or not adolescents stay tobacco-free. As the environment has a big impact, the school has a big challenge to work with the school environment and policies but also with family responsibility, norms and attitudes to tobacco.

Keywords: Adolescents; Cross-Sectional; Salutogenic; Snus-Free; Smoke-Free; Social Environment

\section{INTRODUCTION}

Studies have shown that smoking among teenagers is associated with different factors related to living habits and social environment. Parents influence their children through attitudes, behaviour and tobaccos habits and thus transfer whether smoking is acceptable or not. It is well known that smoke-free parents are less likely to have children who smoke [1,2]. Also, parents' attitudes and active actions against smoking influence whether the children start smoking or not $[3,4]$. Even tobacco use among close friends has a negative effect on tobacco habits among adolescents [5]. Older school mates, smokers or not, become important role models and have a large impact on teenagers and affect their tobacco habits [6]. Many people, especially smokers themselves, believe that smoking among teenagers of their own age is more common than it actually is [5,7]. This misunderstanding can be seen as a risk factor, which facilitates a transition to becoming a smoker.

A large number of factors affect whether young people will be tobacco-free or not. The tobacco habits in the society and the individual's personal qualities are associated with tobacco use. Teenagers who smoke show low self-esteem to a greater extent. Furthermore, they show lower study progress and a feeling of estrangement in school [5] and they drink more alcohol than their smokefree peers [8].

To use snus (the Swedish version of oral moist snuff) is a distinct male habit in Sweden. In the male population, 26 percent report snus-use, whereas only seven percent of females do this [9]. The same pattern is seen among adolescents, 24 percent for boys versus seven percent for girls in upper secondary school (17-year-old) use snus [10]. The difference in tobacco use between the sexes decrease when smoking and snus-use are merged. The few studies about teenagers' debut using snus indicate that snus is introduced later than smoking $[11,12]$. If an adolescent is a smoker, the probability to also becoming 
a snus-user is higher compared to a non-smoker. Adolescents who both smoke and use snus are more addicted to nicotine compared to those who only smoke [13]. One study in Sweden showed a correlation between fathers and their sons using snus [14]. Young people who use snus also drink more alcohol than tobacco-free teenagers [15].

Traditionally, most research has been about risk factors that are related to tobacco use. In this study, we have chosen a salutogenic perspective to find out what is related to being smoke- and snus-free, respectively, among adolescents. The method with positive odds ratios was first used and described in 2002 [16]. Salutogenesis implies a broad perspective with focus on resources, skills and opportunities and access to a social context in the form of family, friends and society structure [17]. An important role for health promotion is to strengthen individuals towards empowerment [18].

\section{Aims}

The aim of this study was to identify factors, which were related to being smoke-free and snus-free, respecttively, among adolescents in relation to adolescents who were smoking and/or using snus, and determine if there were any sex differences.

\section{METHODS}

\subsection{Study Population}

A cross-sectional study was performed among students in year two of upper secondary schools in the autumn of 2009. The study was performed in southern Sweden, with 180,000 inhabitants in eight municipalities. All the 20 schools in the municipalities, both private and municipal, were included in the study. A majority of the students (66 percent) went to schools in the largest municipality.

The study comprised 2666 students. Out of these, 2238 students completed the questionnaire. The response rate was 83.9 percent. A majority of the students were 17 years old on the occasion of the survey, ten percent were younger and two percent were older.

\subsection{Data Collection}

Information about the study was given through letters to and meetings with principals and school nurses at the participating schools. The questionnaires were sent to the schools, and the teachers distributed them to the students who completed them anonymously in school.

Each student put the completed questionnaire in a sealed envelope. An attached form filled out by the teacher gave information on the number of students who participated, the number of students absent due to illness or other reasons and the number of students who refused to participate.

\subsection{Questionnaire}

The questionnaire consisted of 90 questions about health and living habits. Most of the questions were from the Swedish version of the WHO "Health behaviour in school-aged children" 2005/2006 report [19]. The questionnaire items on tobacco habits were the same as in the annual national survey of pupils in grade 9 and year two in upper secondary school conducted by CAN (The Swedish Council for Information on Alcohol and Other Drugs) [10]. These questions had been used on a similar target group and were thus established.

\subsection{Dependent Variables}

The logistic regression analyses were made separately for girls and boys. The dependent variables were smokeand snus-free, respectively. The question "Do you smoke?" had four alternative answers: "Yes", "No, I have quit", "No, but I have tried" and "No, I have never smoked". The dichotomisation was done with the answer "No, but I have tried" and "No, I have never smoked" versus the rest, henceforth named smoke-free. Adolescents who are ex-smokers have a high rate of relapse [20] and in accordance to this, the answer "No, I have quit" was linked to the smoker group.

The question "Do you use snus?" had seven different alternative answers: "No, I have never tried snus", "No, but I have tried", "No, I have quit", "Yes, very seldom", "Yes, sometimes", "Yes, nearly every day", "Yes, every day". In the analysis, the two first answers were dichotomized versus the rest henceforth named snus-free. Snus-users are dichotomized in the same way as smokers, which mean that those who answered "No, I have quit" belong to the group snus-users.

All independent significant variables from the questionnaire were analysed against the outcome variables using $\chi^{2}$ test for girls and boys, respectively.

\subsection{Statistics}

The computer-based SPSS program (version 17.0; SPSS Inc., Chicago. Ill) was used for all data analyses. Following the salutogenic approach to the study, factors associated with not smoking and not using snus were identified using the $\chi^{2}$-test. Variables included in the model were those with a significant $(\mathrm{p}<0.20)$ bivariate relation to the dependent variable and with low correlation $\left(\mathrm{rs}^{2}<0.20\right)$ to each other. All explanatory variables were dichotomized according to their median value. Correlation was analysed using Pearson's r coefficient.

The analyses were performed using a backward procedure, with a step-by-step elimination of non-significant 
predictor variables, until all remaining variables were significant. All analyses were performed with a sex-specific approach, and the results of the analyses are expressed as Positive Odds Ratio (POR) and 95\% Confidence Interval (CI). In the logistic regression model for snus-use, 19 independent variables for girls and 22 variables for boys, were included. For smokers, 29 independent variables were included for girls and 28 for boys, see Table 1. As the variables snus/smoke-free best friend, brother and sister caused substantially increased numbers

Table 1. Variables included in the logistic regression for both smoke-free and snus-free (inclusion is marked $\mathrm{Sn}=\mathrm{snus-free,} \mathrm{Sm}=$ smoke-free, $\mathrm{G}=$ girls, $\mathrm{B}$ = boys). The variables at the last step of the logistic regression are in bold type. Dichotomised variables, the positive part is mentioned first.

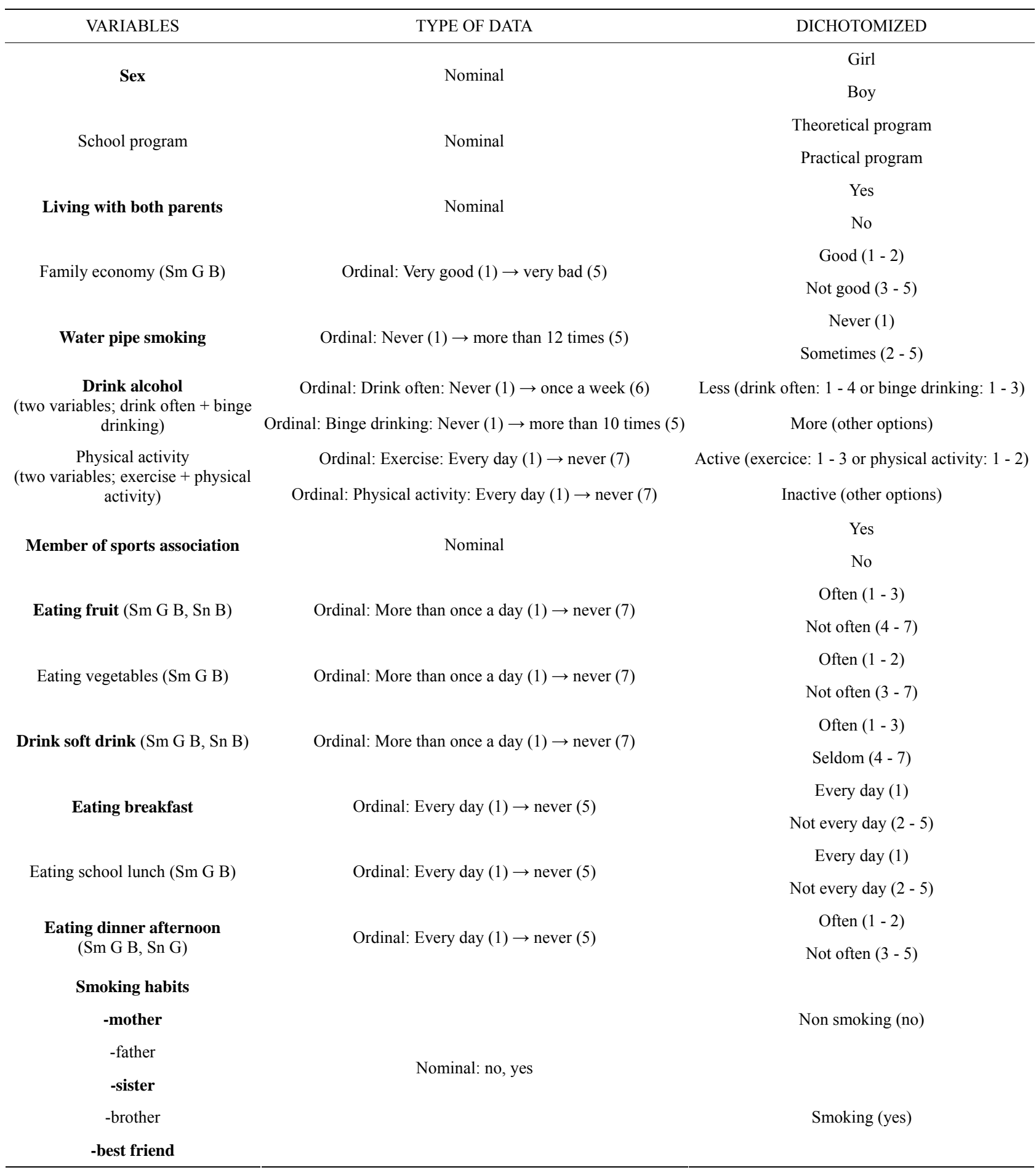




\section{Continued}

Snus habits

-mother
-father
-sister

-brother

-best friend

Sex partners

\section{Health}

Alert and happy

Calm and relaxed (Sm G B, Sn G)

Confident (Sm G)

Satisfied with his/her own body

Satisfied with his/her own looks

Lonely (Sm G)

Outside (Sn B)

Helpless (Sm B, Sn G)

Enjoys (life) (Sm G B, Sn B)

Bully (victimizer)

Is bullied ( $\mathrm{Sm} \mathrm{G} \mathrm{B,} \mathrm{Sn} \mathrm{B)}$

Likes school (Sm G B, Sn B)

Stress at school (Sm G B)

Non-attendance at school
Ordinal: Every day (1) $\rightarrow$ Seldom or never (5)

Ordinal: Every day (1) $\rightarrow$ Seldom or never (5)

Ordinal: Always (1) $\rightarrow$ never (5)

Nominal: Too small (1), small (2), neither nor (3), fat (4), too fat (5), not thought about it (6)

Nominal: very good looking (1), fairly good (2) neither nor (3), not particularly good (4), not at all good looking (5), not thought about it (6)

Ordinal: Always (1) $\rightarrow$ never (5)

Ordinal: Always (1) $\rightarrow$ never (5)

Ordinal: Always (1) $\rightarrow$ never (5)

Ordinal: Very much $(1) \rightarrow$ not at all (4)

Ordinal: Never (1) $\rightarrow$ has bullied several times (3)

Ordinal: Never (1) $\rightarrow$ has been bullied several times (3)

Ordinal: Very much (1) $\rightarrow$ not at all (4)

Ordinal: very calm $(1) \rightarrow$ very stressed (4)

Ordinal: Never $(1) \rightarrow$ several days a week (6)
Not snus users (no)

Snus users (yes)

Few $(1-2)$

Not few $(3-4)$

Good $(1-2)$

Not good (3 - 4)

Often $(1-2)$

Seldom (3 - 5)

Often (1 - 2)

Seldom (3 - 5)

Often (1 - 2)

Seldom (3 - 5)

Satisfied $(3,6)$

Not satisfied (1 - 2, 4 - 5)

Satisfied (1 - 2)

Not satisfied (3 - 6)

Sometimes (1 - 4)

Never (5)

Sometimes (1 - 4)

Never (5)

Sometimes (1 - 4)

Never (5)

Well (1 - 2)

Not so much (3 - 4)

Never (1)

Sometimes $(2-3)$

Never (1)

Sometimes $(2-3)$

$\operatorname{Much}(1-2)$

Not much (3 - 4)

Stressed (1 - 2)

Not stressed (3 - 4)

Little (1 - 2)

Often $(3-6)$ 
of missing values, separate analyses were performed to evaluate the importance of having snus/smoke-free friends and siblings. The Hosmer-Lemeshow test for goodness-of-fit was calculated, and the values for the final model are given. For all analyses, the level of significance was set at $\mathrm{p}<0.05$.

\subsection{Ethics}

Before the start of the study, ethical approval was given by the County Council's local ethics committee. The participants were informed in advance, and at the time for the questionnaire, about the aims and that participation in the study was voluntary. The questionnaire was to be administered anonymously in the classroom and no personal details were to be identifiable in any other way. The design of the questions was such that infringement of personal integrity should be minimal. The study was conducted in agreement with the Swedish Law of Research Ethics, SFS 2003:460.

\section{RESULTS}

Out of the 2238 respondents, 1110 were girls and 1128 were boys. The tobacco habits among the respondents can be seen in Table 2 .

Our results indicate that there was a difference between boys and girls with regard to being snus-free, Table 3 . To be together with a snus-free best friend has the highest relationship for both sexes (POR 10.10 for girls, 7.32 for boys) followed by drinking less alcohol (POR 5.28 for girls, 6.19 for boys). Being snus-free was related to a snus-free mother and sister among girls, while being snus-free was influenced by a brother and father among snus-free boys. Another difference was that boys had influencing factors related to school attendance, not bullying and being a member of a sport association, while being a snus-free girl was related to good health.

There were many identically related variables for being smoke-free for the two sexes. As shown in Table 4, having a smoke-free best friend was the variable with the highest POR for both sexes (POR 7.03 for girls, 9.03 for boys). To drink less alcohol and being smoke-free was related for both sexes (POR 3.97 for girls, 3.17 for boys) as well, just like living with both parents (POR 1.54 for girls, 1.68 for boys). The experience of having good health and regular eating habits were influencing variables for boys but not for girls.

\section{DISCUSSION}

Traditionally, most studies are focused on risk-factors for being a smoker. This study turns the perspective

Table 2. Tobacco habits among the respondents.

\begin{tabular}{ccccc}
\hline & \multicolumn{3}{c}{ Girls } & \multicolumn{2}{c}{ Boys } \\
\cline { 2 - 5 } & $\mathrm{n}=1107$ & $\%$ & $\mathrm{n}=1112$ & $\%$ \\
\hline Smoke-free & 837 & 75.6 & 856 & 77 \\
Smokers & 270 & 24.4 & 256 & 23 \\
\hline \multirow{2}{*}{ Girls } & \multicolumn{2}{c}{ Boys } \\
\cline { 2 - 6 } Snus-free & 1032 & 95.1 & 774 & 70.2 \\
Snus-users & 53 & 4.9 & 328 & 29.8 \\
\hline
\end{tabular}

Table 3. Varibales related to being snus-free, POR and 95\% CI for girls and boys, respectively. Significant figures are in bold.

\begin{tabular}{|c|c|c|c|c|}
\hline \multirow{2}{*}{ SNUS-FREE } & \multicolumn{2}{|c|}{ Girls $(n=1003)$} & \multicolumn{2}{|c|}{ Boys $(n=954)$} \\
\hline & POR & $95 \% \mathrm{CI}$ & POR & $95 \% \mathrm{CI}$ \\
\hline Drinks alcohol: less & 5.28 & $1.55-17.96$ & 6.19 & $3.65-10.49$ \\
\hline Snus-free mother: yes & 3.14 & $1.02-9.65$ & 0.63 & $0.28-1.43$ \\
\hline Health: good & 3.12 & $1.64-5.95$ & 1.17 & $0.64-2.13$ \\
\hline Smokes water pipe: never & 2.37 & $1.12-5.01$ & 2.74 & $1.89-3.97$ \\
\hline Sex partners: few & 2.36 & $1.27-4.38$ & 1.90 & $1.35-2.66$ \\
\hline Bullies: never & 2.77 & $0.94-8.18$ & 1.83 & $1.16-2.88$ \\
\hline Non-attendance at school: little & 1.77 & $0.93-3.36$ & 1.60 & $1.16-2.23$ \\
\hline Member of sports association: yes & 1.27 & $0.57-2.81$ & 1.80 & $1.30-2.49$ \\
\hline Snus-free father: yes & 0.97 & $0.48-1.95$ & 1.60 & $1.15-2.23$ \\
\hline Snus-free best friend: yes ${ }^{*}$ & 10.10 & $5.00-20.17$ & 7.32 & $5.05-10.62$ \\
\hline Snus-free sister: yes ${ }^{* *}$ & 4.87 & $1.48-16.05$ & 2.41 & $0.87-6.24$ \\
\hline Snus-free brother: yes ${ }^{* * *}$ & 1.97 & $0.92-4.22$ & 3.32 & $2.06-5.36$ \\
\hline
\end{tabular}

Hosmer and Lemeshow test for the analysis about snus-free were 0.849 for girls and 0.034 for boys and Nagelkerke R Square 0.186 and 0.325 , respectively. ${ }^{*}$ Girls $\mathrm{n}=961$; Boys $\mathrm{n}=889 ;{ }^{* *}$ Girls $\mathrm{n}=571$; Boys $\mathrm{n}=633 ;{ }^{* * *}$ Girls $\mathrm{n}=598$; Boys $\mathrm{n}=633$. 
Table 4. Variables related to being smoke-free, POR and 95\% CI for girls and boys, respectively. Significant figures are in bold.

\begin{tabular}{|c|c|c|c|c|}
\hline \multirow{2}{*}{ SMOKE-FREE } & \multicolumn{2}{|c|}{ Girls $(n=963)$} & \multicolumn{2}{|c|}{ Boys $(\mathrm{n}=945)$} \\
\hline & POR & $95 \% \mathrm{CI}$ & POR & $95 \% \mathrm{CI}$ \\
\hline Drinks alcohol: less & 3.97 & $2.43-6.56$ & 3.17 & $1.82-5.53$ \\
\hline Member of sports association: yes & 3.14 & $2.05-4.83$ & 2.80 & $1.90-4.12$ \\
\hline Smokes water pipe: never & 2.46 & $1.64-3.69$ & 2.83 & $1.83-4.36$ \\
\hline Smoke-free mother: yes & 2.25 & $1.45-3.49$ & 1.82 & $1.15-2.87$ \\
\hline Non-attendance at school: little & 2.18 & $1.48-3.28$ & 1.97 & $1.36-2.84$ \\
\hline Sex partners: few & 2.09 & $1.39-3.16$ & 2.40 & $1.64-3.52$ \\
\hline Smoke-free father: yes & 1.95 & $1.25-3.03$ & 1.51 & $0.93-2.44$ \\
\hline Eats breakfast: every day & 1.90 & $1.29-2.77$ & 1.74 & $1.20-2.51$ \\
\hline Satisfied with his/her body: yes & 1.68 & $1.12-2.51$ & 0.92 & $0.62-1.36$ \\
\hline Drinks soft drinks: no & 1.60 & $1.06-2.35$ & 1.45 & $0.95-2.01$ \\
\hline Lives with both parents: yes & 1.54 & $1.05-2.24$ & 1.68 & $1.15-2.47$ \\
\hline Health: good & 1.27 & $0.77-2.11$ & 2.59 & $1.49-4.50$ \\
\hline Eats dinner, afternoon: yes & 0.93 & $0.60-1.44$ & 1.90 & $1.24-2.91$ \\
\hline Smoke-free best friend: yes ${ }^{*}$ & 7.03 & $4.74-10.41$ & 9.03 & $5.88-13.86$ \\
\hline Smoke-free sister: yes ${ }^{* *}$ & 3.40 & $1.92-6.02$ & 1.72 & $0.95-3.12$ \\
\hline Smoke-free brother: yes ${ }^{* * *}$ & 1.76 & $1.03-2.99$ & 2.77 & $1.47-5.23$ \\
\hline
\end{tabular}

Hosmer and Lemeshow test for the analysis of smoke-free were 0.407 for girls and 0.256 for boys and Nagelkerke R Square 0.4600 .386 , respectively. ${ }^{*}$ Girls $\mathrm{n}$ $=962 ;$ Boys $n=864 ;{ }^{* *}$ Girls $n=557 ;$ Boys $n=601 ;{ }^{* * *}$ Girls $n=594 ;$ Boys $n=583$.

around. It has a salutogenic approach and therefore studies variables that relate to being smoke-free and snusfree, respectively. It is important to learn why young people can remain tobacco-free. An important main goal of health promotion is creating supportive environments thus it makes it easier for individuals to take responsibility for their choices. A key concept is empowerment seen as a process through which people gain greater control over decisions and actions, which affect their health [21]. The schools have a key role in developing a health promotion arena to help adolescents make healthy choices in order to have good living habits, but also to strengthen the individual recourses and the adolescent's self-efficacy.

Understanding why adolescents have not used tobacco could help researchers develop strategies for designing health-promotion programs to reach teenagers before they begin experimenting with tobacco and to assist those who start using tobacco [22]. The most important task is not to identify single risk factors and remove them, but to be one step ahead of them. The health promotion interventions must focus on how to decrease the total burden of risk factors and increase the access to protective factors. This study can also give support to the idea and approach of health-promoting environments for adolescents. The schools' tobacco or health policy must include the overall environment and people's living habits.
Since snus-use is primarily a male habit limited to Scandinavia, there are not many studies focused on gender differences $[9,10]$. Our study indicates that important protective factors for being free from snus-use are absence of snus in the near environment and generally healthy living habits. Obviously, the strongest factor related to being snus-free, for both girls and boys, is to have a snus-free best friend. Distinct differences between the sexes were also seen in such a way that male (father, brother) snus-free models influence boys, while female (mother, sister) snus-free models were related to girls being snus-free. An unpublished study verifies that boys expressed that snus-use was very masculine (Author, submitted). One limitation in the results was the poor Hosmer and Lemeshow test value for snus-free boys. Possibly there is an extended set of potential predictors.

This study showed that a smoke-free best friend was clearly the strongest factor related to being smoke-free for both sexes. To the best of our knowledge, no references from other studies can confirm the finding that smoke-free relations are important for remaining smokefree. However, many studies confirm that smoking in the near environment is more common among smokers [5]. Our study showed that the correlation was weaker with regard to smoke-free or snus-free parents compared to best friend. The social influence is not only if parents and/or friends use tobacco or not, but norms are also 
important. Parents and peers influence the adolescents' behaviour and intention to become a smoker through different processes. Descriptive norms influence the teenagers' behaviour to a greater extent than subjective norms, while subjective norms have a greater impact on the intention to smoke. A study has shown that parents have an effect on both descriptive and subjective norms, but peers only influence descriptive norms of smoking behaviour [23]. Peer influences are more important for teenagers, then influences from parents. It is not surpriseing that adolescents who live with both parents are less likely to smoke than those who live with one parent, since there is a larger proportion of single parents who smoke [24].

All tobacco-free environments are resources for keeping adolescents tobacco-free. The results of this study indicate that being a member of a sports association is a related factor for both smoke-free girls and boys, as well as snus-free boys. Therefore, sports associations may be important as health promotion arenas and they have a responsibility to declare their support for a healthy life-style. A social context may imply protective factors or the other way around. In Sweden, for example, some sports (e.g. ice hockey) are associated with the use of snus [25]. One study showed that adolescents participating in team sports had a lower incidence of tobacco use compared to those involved in technical or strength sports [26]. The analysis of this study did not differentiate between the various types of sports activities, just membership in a sports association.

The relationship between low alcohol consumption and to be snus-free is stronger than being smoke-free. A previous Swedish study has shown that boys who use snus have an estimated alcohol intake that is five times higher than that of tobacco-free boys [15]. The friends that non-smokers associate with seem to have norms and habits mainly similar to their own. To have a smoke-free best friend interacts with low alcohol consumption, and one explanation for this can be that non-smokers consume less alcohol than smokers do [27], and this is also seen as a related factor in this study. This indicates that social factors in the near environment are important protective factors for both sexes being tobacco-free.

Having good health is more common among smokefree boys and snus-free girls. This relationship cannot be seen for smoke-free girls, and a reason for this could be that even smoke-free girls report poor health to a greater extent than boys do in our study. Other studies confirm that good health is reported to a higher degree among tobacco-free adolescents than among tobacco users, but also that boys report good health more often than girls do [28]. There are probably other factors that have a greater impact on girls to be smoke-free than those found in our study.
From this study's results, a larger number of social environmental factors are found for smoke-free girls than for boys. The results also show that more variables are related to being smoke-free compared to being snus-free. An explanation to this may be that the smoke-free group is larger than the snus-free group for both sexes, especially for girls, where only five percent are snus-users. Even in national surveys, snus-use is less common among girls [10].

This study is a comprehensive, cross-sectional study of students in the second year of upper secondary school. Reasons for the high participation rate of 84 percent may be that the survey was conducted during school hours, and that the students responded anonymously. The reasons not to participate were illness or not accepted absence, but the student could also choose to abstain from participation even if they were present.

There is always a risk that self-reported smoking habits among young people are believed to be under-reported. According to a Swedish study, there was a 98 percent concordance between self-reported smoking habits and cotinine in saliva [29]. There is no reason to believe that it would be different for snus-use.

For both sexes, an association exists between being smoke-free and snus-free $(\mathrm{p}<0.001)$, and these variables are therefore not included as independent variables in the analysis. If snus-users had been excluded from the smoke-free group, the group had been tobacco-free. Since the aim was to study the factors related to being smoke-free and snus-free, respectively, in comparison to those who were smoking or using snus, respectively, the smoke-free group may include snus-users, and the snus-free group may include smokers. One indication for this was that smoking was also a risk factor for starting to use snus, and vice-versa [13].

There are not many studies available on the salutogenic perspective of tobacco habits, and the lack of studies is obvious when it comes to snus-use. In this study, we used a traditional questionnaire but tried to look at the results from a salutogentic perspective. Therefore, data were presented as POR in order to focus on the predictors of being smoke- or snus-free, instead of the traditional way of studying why people smoke or use snus. However, there are difficulties involved in proceeding from a salutogenetic perspective in a traditional questionnaire. It is a challenge to find measurement methods with a salutogenic approach to adolescents' living habits and health, and how to find resources and positive factors and not only ask for risk factors. The results showed to what degree each factor was protective with regard to remaining smoke- or snus-free, compared to not having this protective factor. The results showed a relationship between being smoke-free or snus-free among adolescents, and they attempt to explain in a new way why 
many adolescents do not use tobacco.

\section{CONCLUSION}

The results show that a tobacco-free environment has a major influence on whether or not adolescents remain tobacco-free. As the environment has a large impact, the school has a great challenge to work not only with the school environment and policies but also with family responsibilities, norms and attitudes to tobacco. A healthpromoting school can be characterized as being a school that is constantly strengthening its position as a healthy setting for learning and working to give strength to and support healthy choices. Because of its salutogenic approach, this study is unique and may contribute to new ways of looking at tobacco prevention and adopt a health-promotion view that focuses on resources at both individual and group levels. There is a need for further research to explore why some adolescents remain tobacco-free, and to develop new strategies with a healthpromotion approach. As part of this, there is need to develop an instrument for measuring salutogenetic factors for adolescents.

\section{REFERENCES}

[1] Murray, M., Kiryluk, S. and Av, S. (1985) Relation between parents' and children's smoking behaviour and attitudes. Journal of Epidemiology and Community Health, 39, 169-174. doi:10.1136/jech.39.2.169

[2] Scragg, R.L.M. (2007) Influence of smoking by family and best friend on adolescent tobacco smoking: Results from the 2002 New Zealand national survey of year 10 students. Australian and New Zealand Journal of Public Health, 31, 217-223. doi:10.1111/j.1467-842X.2007.00051.x

[3] Andersen, M.R., Leroux, B.G., Bricker, J.B., Rajan, K.B. and Av, P. (2004) Antismoking parenting practices are associated with reduced rates of adolescent smoking. Archives of Pediatrics \& Adolescent Medicine, 158, 348352.

[4] Sargent, J.D. and Dalton, M. (2001) Does parental disapproval of smoking prevent adolescents from becoming established smokers? Pediatrics, 108, 1256-1262. doi:10.1542/peds.108.6.1256

[5] US Department of Health and Human Services (2012) Preventing tobacco use among youth and young adults: A report of the surgeon general. Centers for Disease Control and Prevention, National Center for Chronic Disease Prevention and Health Promotion, Office on Smoking and Health, Atlanta.

[6] Bricker, J.B., Rajan, K.B., Sarason, I.G. and Peterson, A.V. Jr. (2007) The role of schoolmates' smoking and nonsmoking in adolescents' smoking transitions: A longitudinal study. Addiction, 102, 1665-1675. doi:10.1111/j.1360-0443.2007.01945.x

[7] Conrad, K.M., Flay, B.R. and Hill, D. (1992) Why chil- dren start smoking cigarettes: Predictors of onset. British Journal of Addiction, 87, 1711-1724. doi:10.1111/j.1360-0443.1992.tb02684.x

[8] Wetzels, J.J., Kremers, S.P., Vitória, P.D. and De Vries, H. (2003) The alcohol-tobacco relationship: A prospective study among adolescents in six European countries. $\mathrm{Ad}$ diction, 98, 1755-1763. doi:10.1111/j.1360-0443.2003.00553.x

[9] Boström, G. (2007) Hälsa på lika villkor. http://www.fhi.se/templates/Page_ 12661.aspx

[10] Henriksson, C. and Leifman, H. (2011) Skolelevers drogvanor. Centralförbundet för Alkoholoch Narkotikaupplysning, Stockholm, 260.

[11] Edvardsson, I., Lendahls, L. and Hakansson, A. (2009) When do adolescents become smokers? Annual sevenyear population-based follow-up of tobacco habits among 2000 Swedish pupils: An open cohort study. Scandinavian Journal of Primary Health Care, 27, 41-46. doi: $10.1080 / 02813430802588675$

[12] Galanti, M.R., Rosendahl, I. and Wickholm, S. (2008) The development of tobacco use in adolescence among "snus starters" and "cigarette starters": An analysis of the Swedish "BROMS" cohort. Nicotine \& Tobacco Research, 10, 315-323. doi:10.1080/14622200701825858

[13] Haukkala, A., Vartiainen, E. and Hakansson, A. (2006) Progression of oral snuff use among Finnish 13 - 16year-old students and its relation to smoking behaviour. Addicion, 101, 581-589. doi:10.1111/j.1360-0443.2005.01346.x

[14] Rosendahl, K.I., Galanti, M.R., Gilljam, H. and Ahlbom, A. (2003) Smoking mothers and snuffing fathers: Behavioural influences on youth tobacco use in a Swedish cohort. Tobacco Control, 12, 74-78. doi:10.1136/tc.12.1.74

[15] Wickholm, S.G.M., Söder, B. and Gilljam, H. (2003) Cigarette smoking, snuff use and alcohol drinking: Coexisting risk behaviours for oral health in young males. Community Dentistry and Oral Epidemiology, 31, 269-274. doi:10.1034/j.1600-0528.2003.00046.x

[16] Ejlertsson, G., Eden, L. and Leden, I. (2002) Predictors of positive health in disability pensioners: A populationbased questionnaire study using positive odds ratio. $B M C$ Public Health, 2, 20. doi:10.1186/1471-2458-2-20

[17] Lindstrom, B. and Eriksson, M. (2011) From health education to healthy learning: Implementing salutogenesis in educational science. Scandinavian Journal of Public Health, 39, 85-92. doi:10.1177/1403494810393560

[18] Koelen, M.A. and Lindstrom, B. (2005) Making healthy choices easy choices: The role of empowerment. European Journal of Clinical Nutrition, 59, S10-S15, Discussion S6-S23.

[19] Currie, C. (2008) Inequalities in young people's health HBSC international report from the 2005/2006 survey. World Health Organization, Copenhagen.

[20] Bancej, C., O’Loughlin, J., Platt, R.W., Paradis, G. and Gervais, A. (2007) Smoking cessation attempts among adolescent smokers: A systematic review of prevalence studies. Tobacco Control, 16, e8.

doi:10.1136/tc. 2006.018853 
[21] Nutbeam, D. (1998) Health promotion glossary. World Health Organisation, Geneva.

[22] Kulbok, P.A., Rhee, H., Botchwey, N., Hinton, I., Bovbjerg, V. and Anderson, N.L. (2008) Factors influencing adolescents' decision not to smoke. Public Health Nursing, 25, 505-515. doi:10.1111/j.1525-1446.2008.00737.x

[23] Vitoria, P.D., Salgueiro, M.F., Silva, S.A. and De Vries, H (2011) Social influence, intention to smoke, and adolescent smoking behaviour longitudinal relations. British Journal of Health Psychology, 16, 779-798. doi:10.1111/j.2044-8287.2010.02014.x

[24] Statens Folkhälsoinstitut (2010) Folkhälsopolitisk rapport 2010: Framtidens folkhälsa: Allas ansvar. Statens Folkhälsoinstitut, Stockholm.

[25] Rolandsson, M. and Hugoson, A. (2003) Changes in tobacco habits. A prospective longitudinal study of tobacco habits among boys who play ice hockey. Swedish Dental Journal, 27, 175-184.
[26] Wichstrom, T. and Wichstrom, L. (2009) Does sports participation during adolescence prevent later alcohol, tobacco and cannabis use? Addiction, 104, 138-149. doi:10.1111/i.1360-0443.2008.02422.x

[27] Wetzels, J.J., Kremers, S.P., Vitoria, P.D. and De Vries, H. (2003) The alcohol-tobacco relationship: A prospective study among adolescents in six European countries. $\mathrm{Ad}$ diction, 98, 1755-1763. doi:10.1111/j.1360-0443.2003.00553.x

[28] Nygren, K., Janlert, U. and Nygren, L. (2011) Norm compliance and self-reported health among Swedish adolescents. Scandinavian Journal of Public Health, 39, 44-50. doi:10.1177/1403494810389846

[29] Post, A.G.H., Rosendahl, I., Meuling, L., Bremberg, S. and Galanti, M.R. (2005) Validity of self reports in a cohort of Swedish adolescent smokers and smokeless tobacco (snus) users. Tobacco Control, 14, 114-117. doi:10.1136/tc.2004.008789 